\title{
Development and evaluation of a handheld type 6 DoF midair haptic device using asymmetric vibration and a presentation force vectoring mechanism
}

\section{Yuto Okuda}

KDDI

Shunsuke Komizunai ( $\sim$ komizunai@ssi.ist.hokudai.ac.jp )

Hokkaido University

Atsushi Konno

Hokkaido University

\section{Research Article}

Keywords: haptic device, pseudo haptics, asymmetric vibration, biased acceleration vibration, traction sensation, force sensation

Posted Date: January 18th, 2021

DOl: https://doi.org/10.21203/rs.3.rs-147091/v1

License: (c) (1) This work is licensed under a Creative Commons Attribution 4.0 International License.

Read Full License 


\section{Abstract}

This paper describes a handheld type aerial haptic device with $6 \mathrm{DoF}$ (degree of freedom) using pseudohaptics by asymmetric vibration. By introducing a original presentation force vectoring mechanism, 6 DoF force sense presentation and compactness suitable for handheld use with a small number of vibrators are realized together. In addition, a relationship between the drive input and output (presentation force sense) of the developed device is formulated, and its inverse problem solving method for obtaining the drive input that realizes a desired presentation force sense is derived. Furthermore, a user test clarified the direction in which this device can / cannot effectively exert force.

\section{Full Text}

Due to technical limitations, full-text HTML conversion of this manuscript could not be completed. However, the manuscript can be downloaded and accessed as a PDF.

\section{Figures}
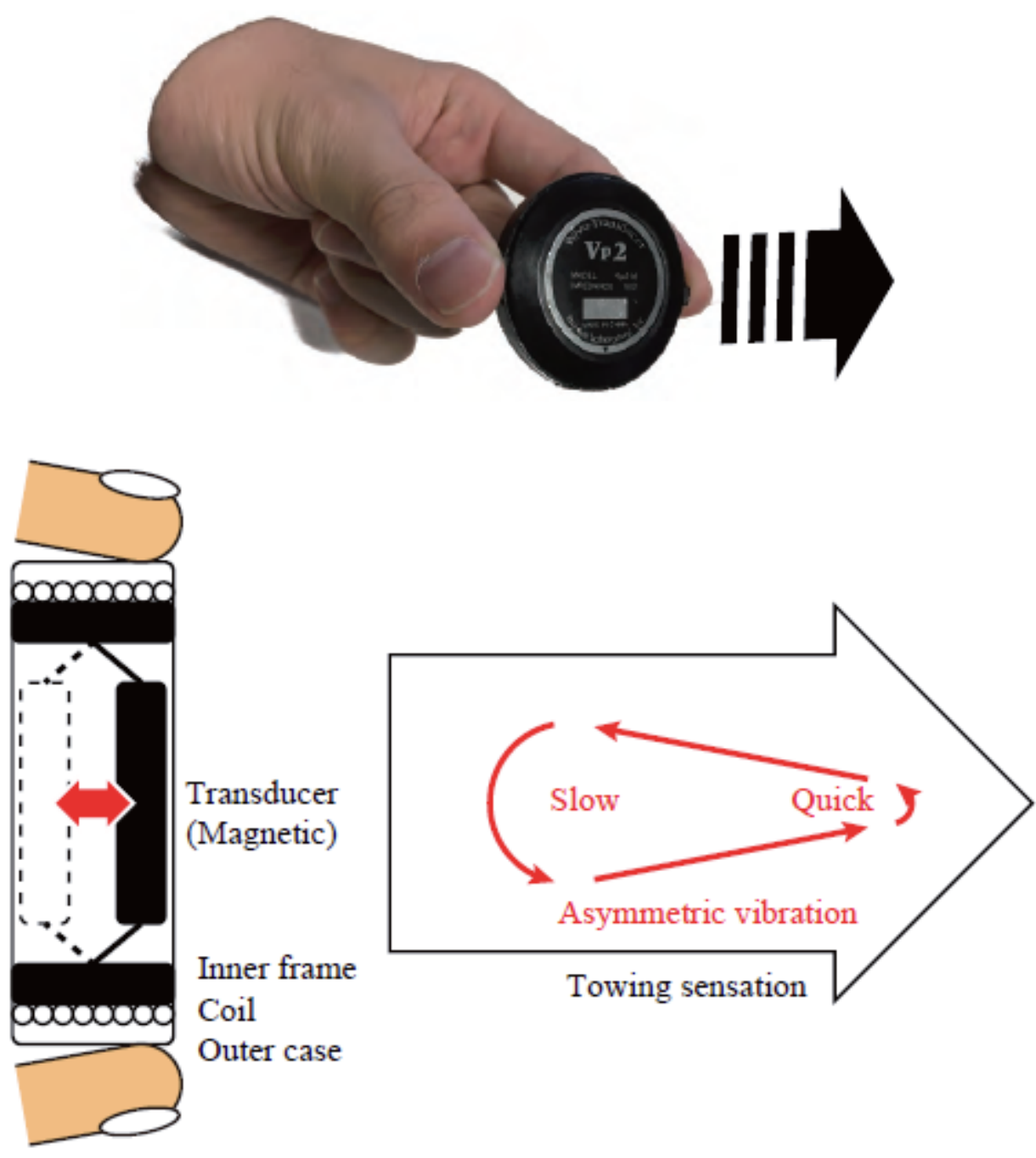

Figure 1 
Generating traction sensation by asymmetric vibration

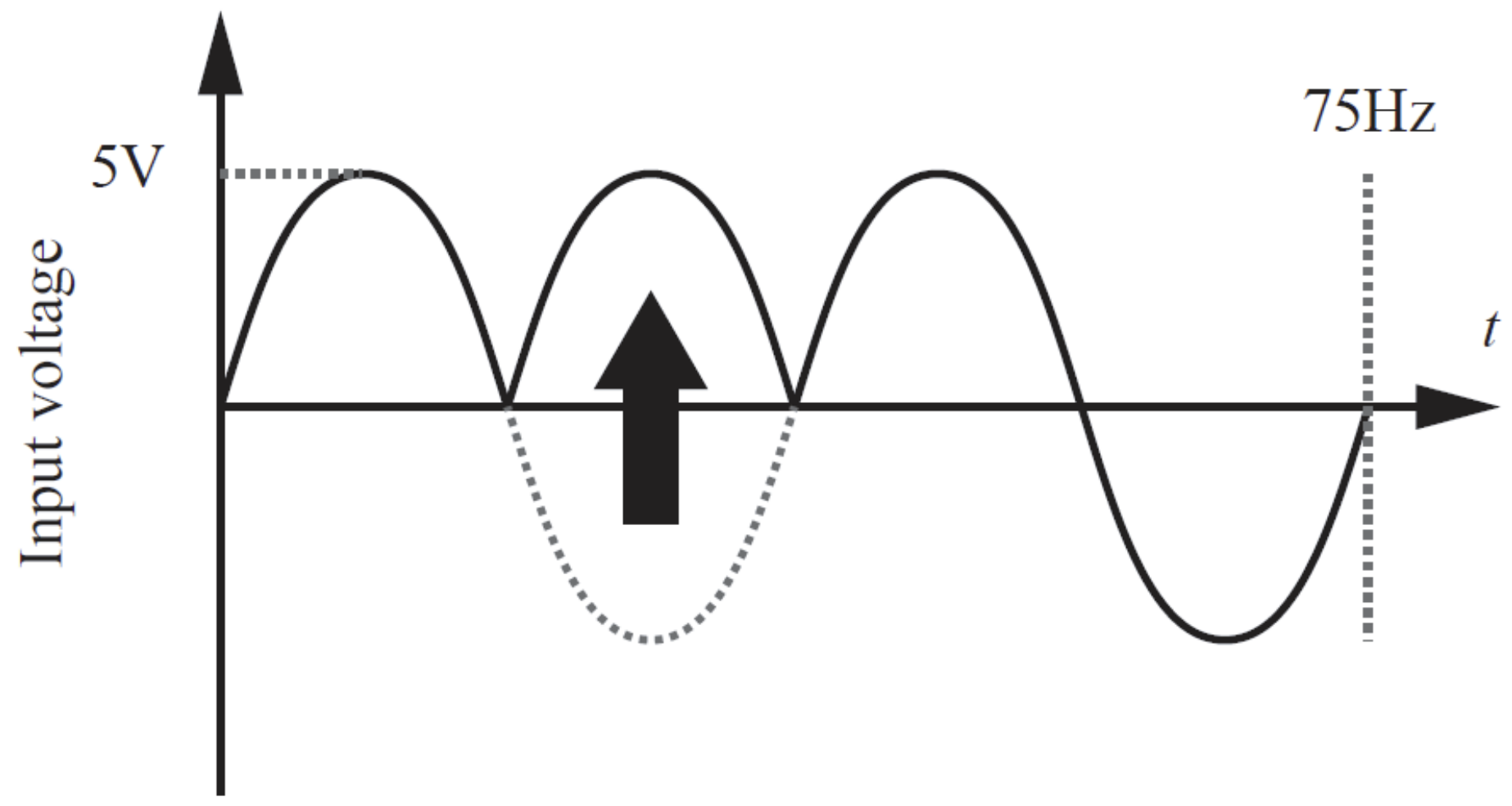

Figure 2

An approximate input voltage waveform for asymmetric vibration
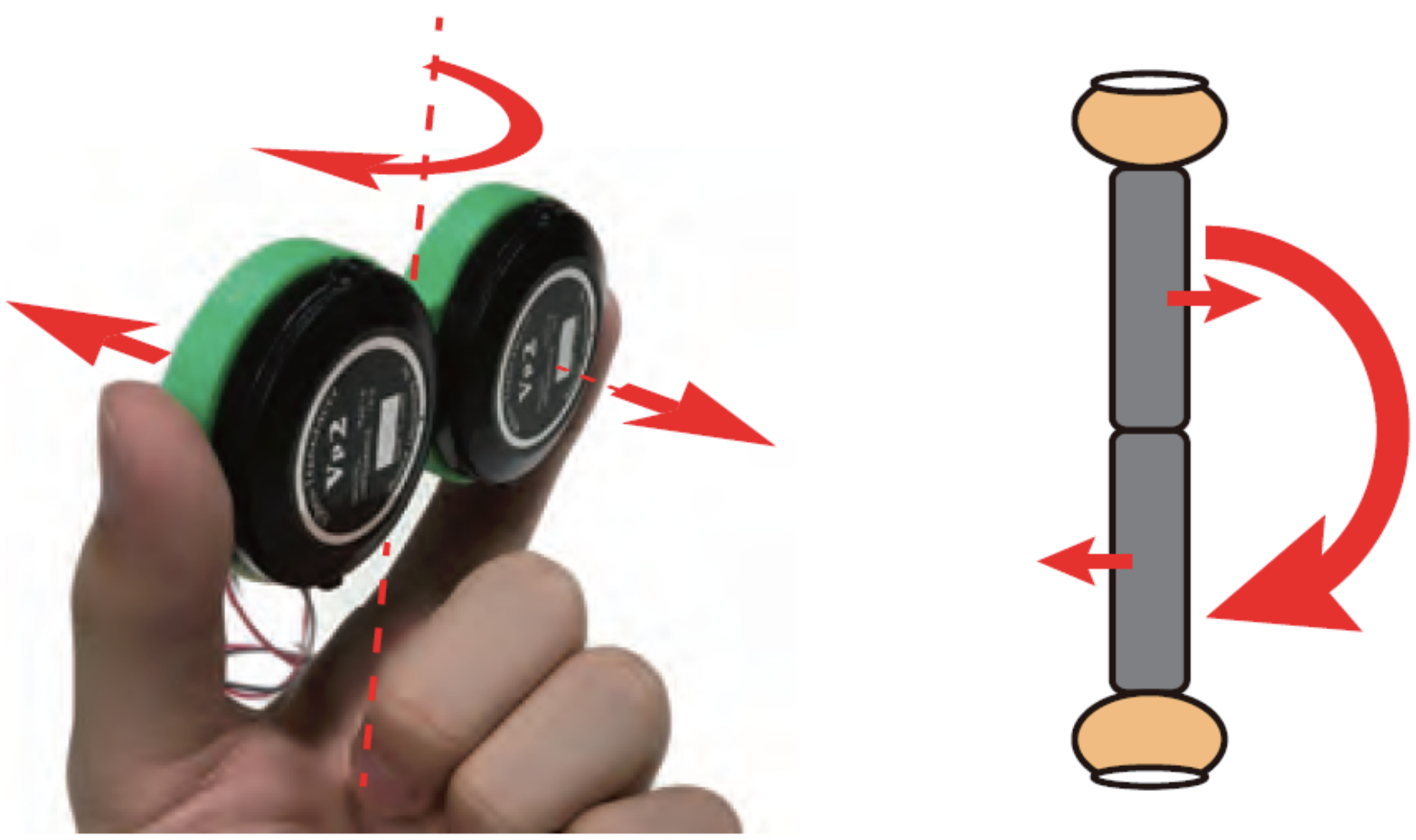
Figure 3

Synthesis of rotational sensation by combining two vibrators (translational traction sensation)

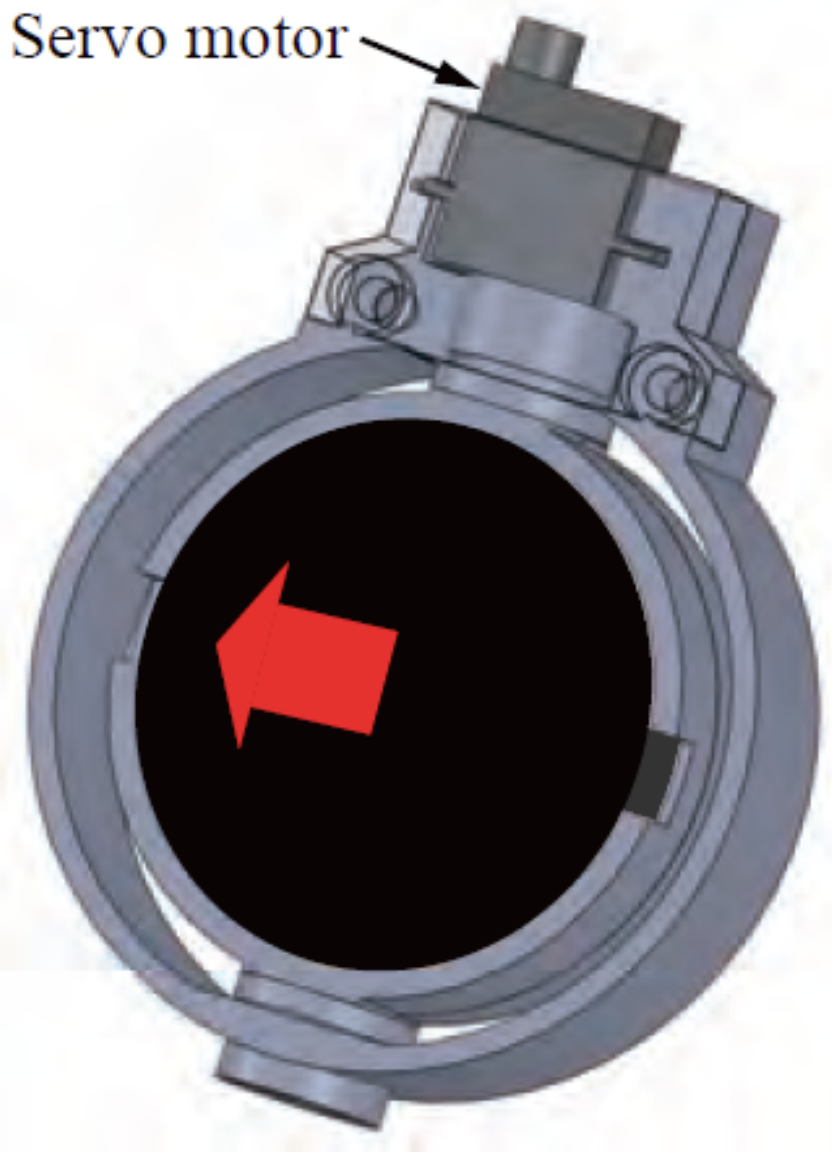

(a)

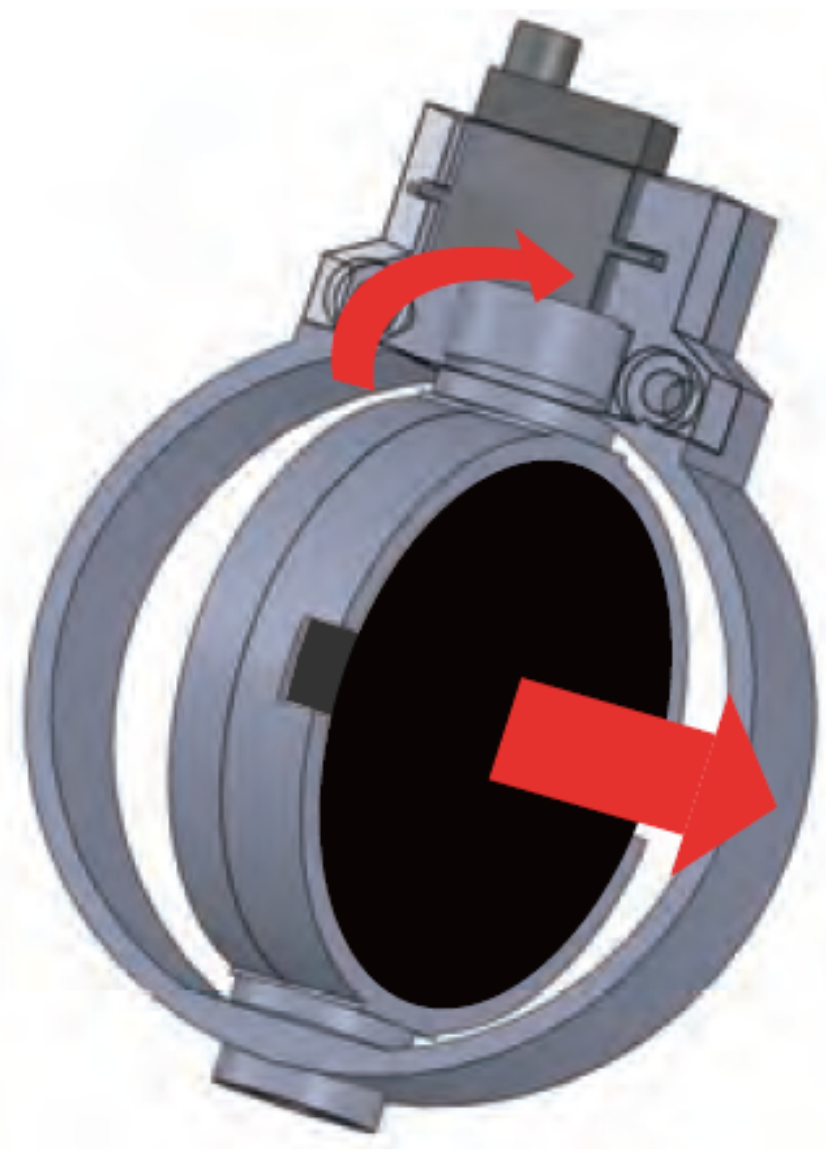

(b)

\section{Figure 4}

A mechanism for vectoring the presented force (traction sensation). (a) shows a standard state, (b) shows a maximum vectoring state 


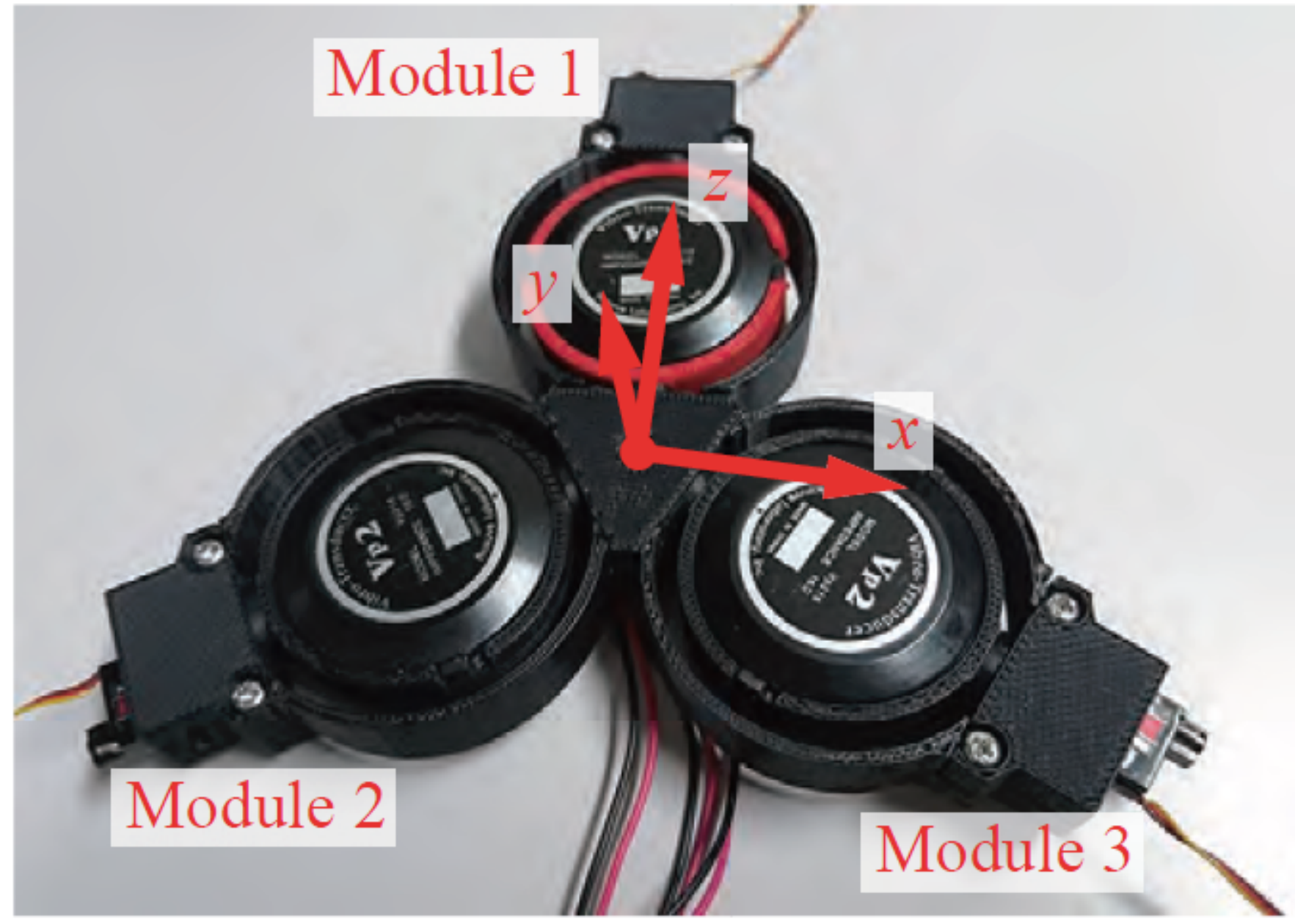

Figure 5

An overview and a local coordinate system of the developed 6 DoF midair haptic device 


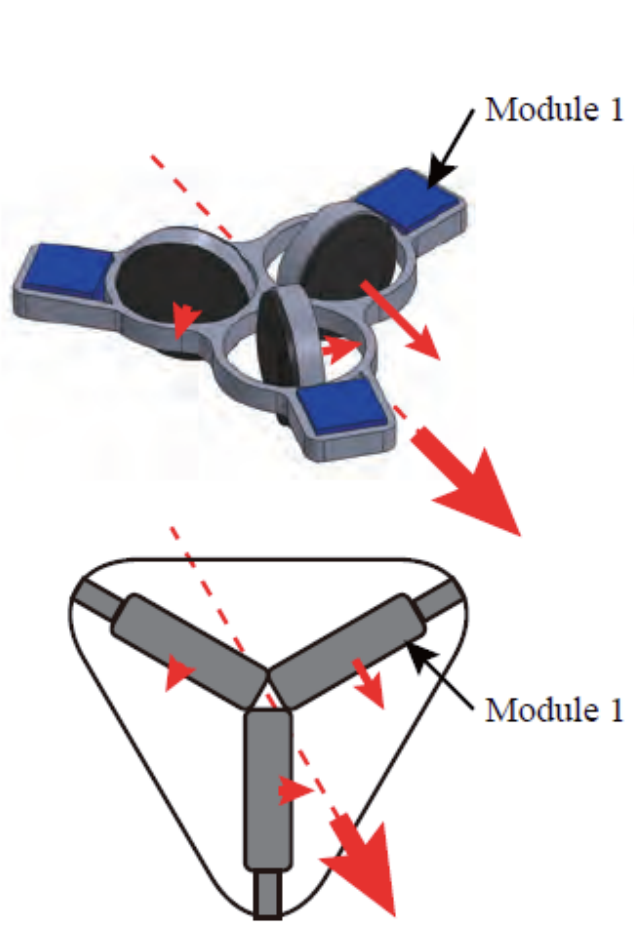

(a) $f_{x}$
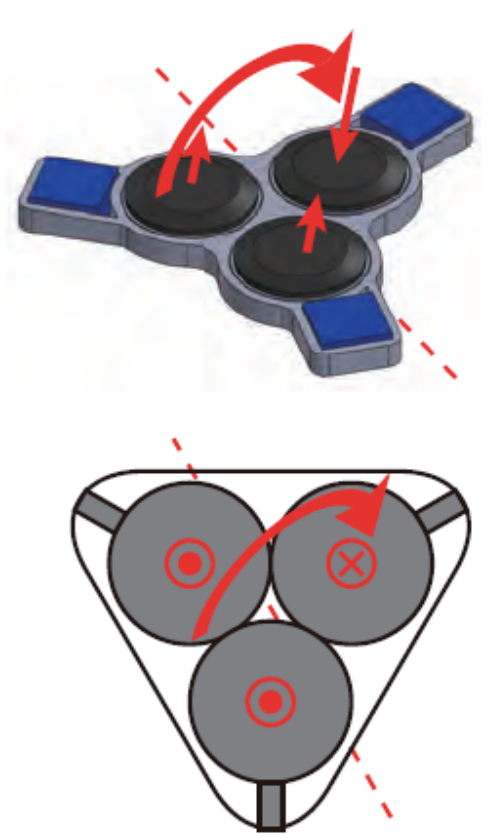

(d) $-\tau_{x}$
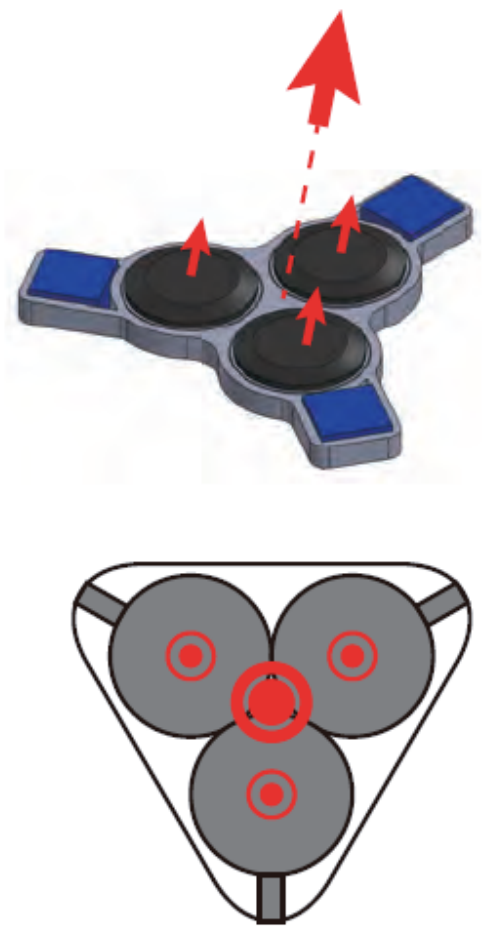

(b) $f_{y}$
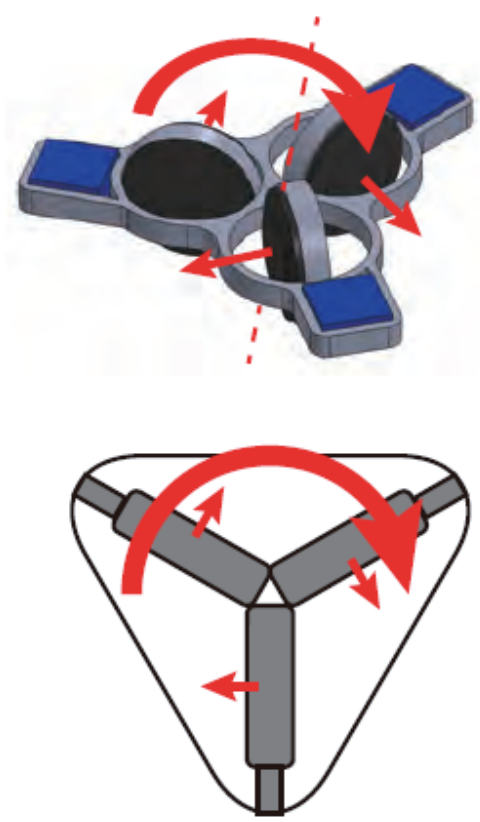

(e) $-\tau$
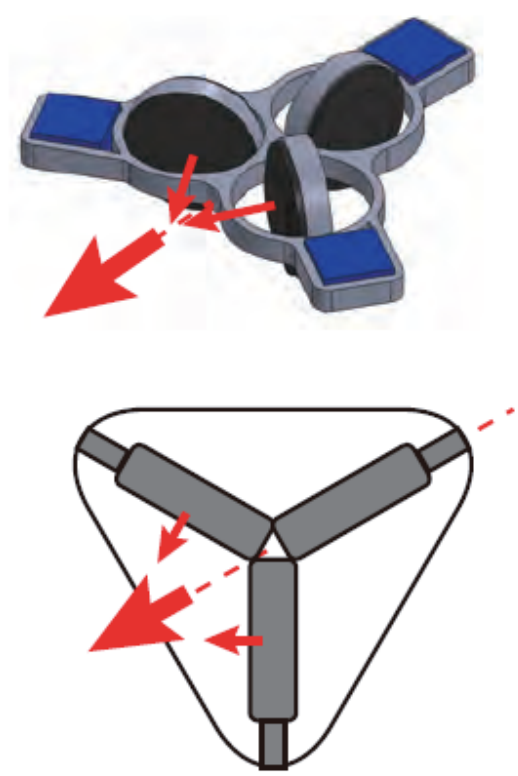

(c) $-f_{z}$
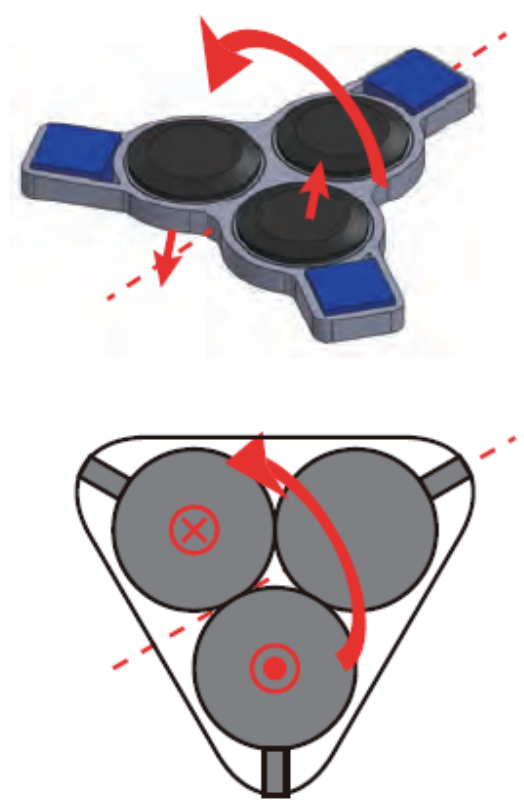

(f) $-\tau$

\section{Figure 6}

Schematic diagrams of how the device moves and how the presentation force is composed. In each figure, an upper right part is the module 1 , and the $y$-axis of the device faces the front side of this paper. small arrows indicate the presentation force of each vibrator, and large arrows indicate the composited force. (a) - (c) show the composition of the translational force in the direction of the $x$-axis $f x$, the $y$-axis fy, 
the $z$-axis $-f z$ respectively, $(d)-(f)$ show the composition of the rotational force (torque) around the $x$-axis $-\tau x$, the $y$-axis $-\tau y$, the $z$-axis - $\tau z$ respectively

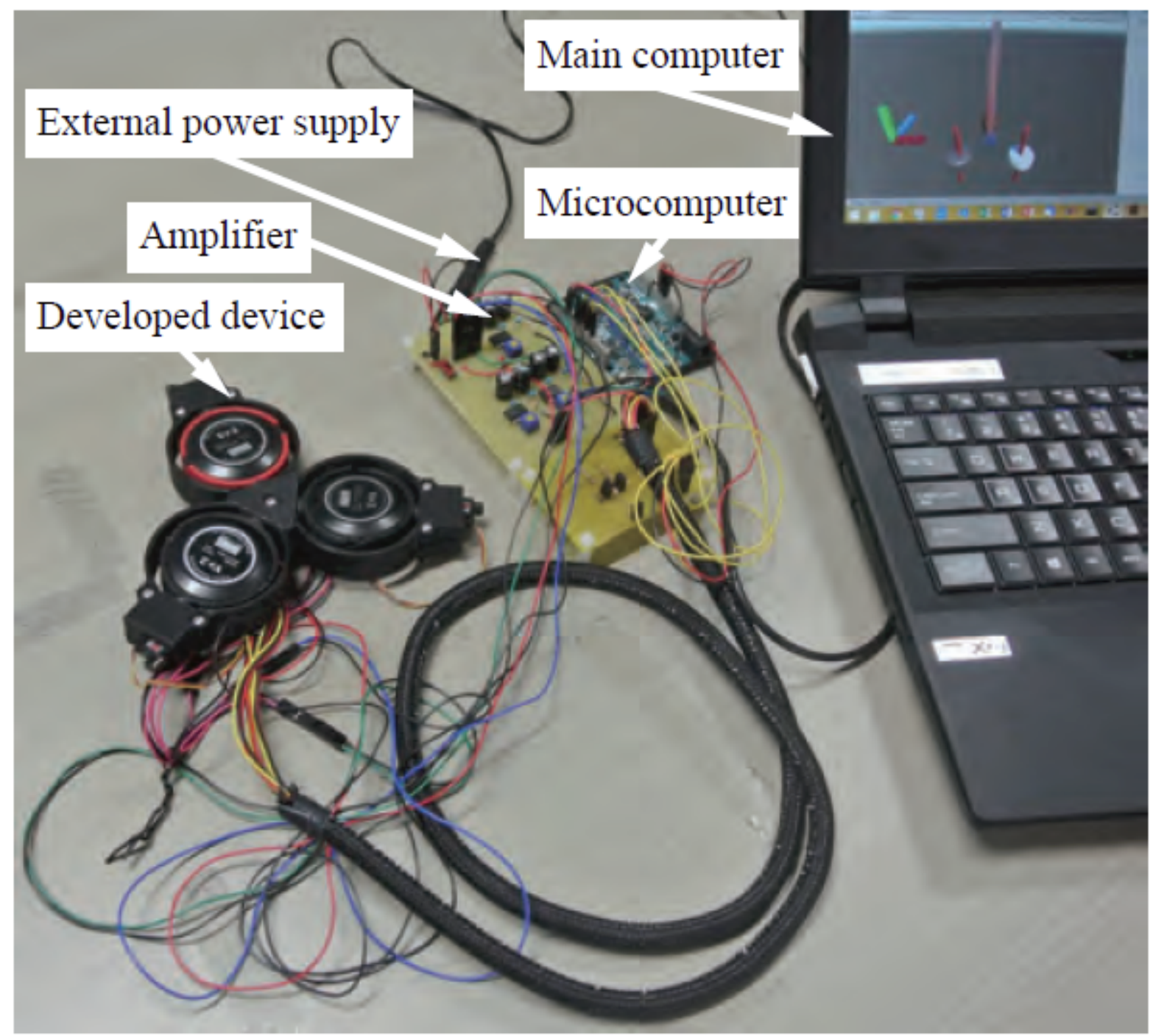

Figure 7

An overview of an electrical system for controlling the developed device 


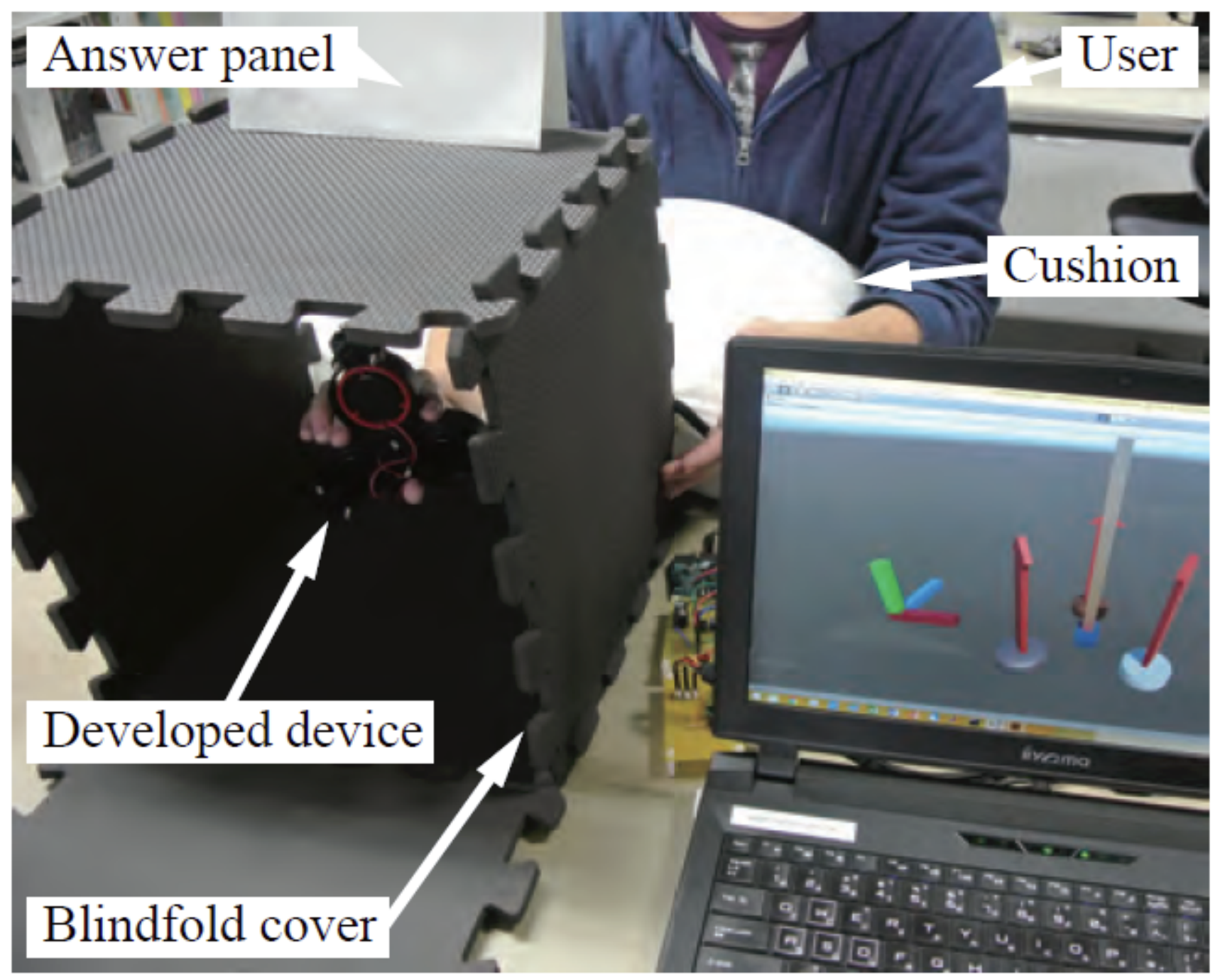

Figure 8

An overview of the user test setup 


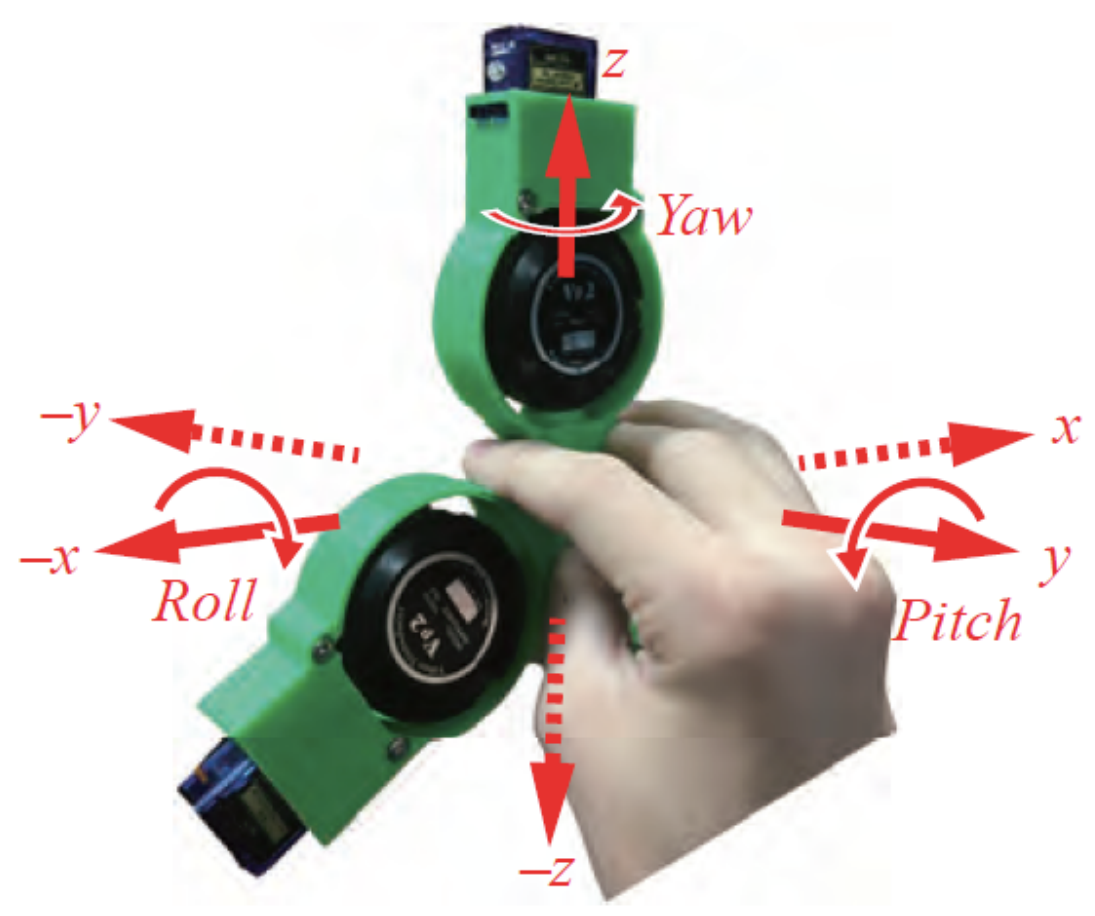

(a)

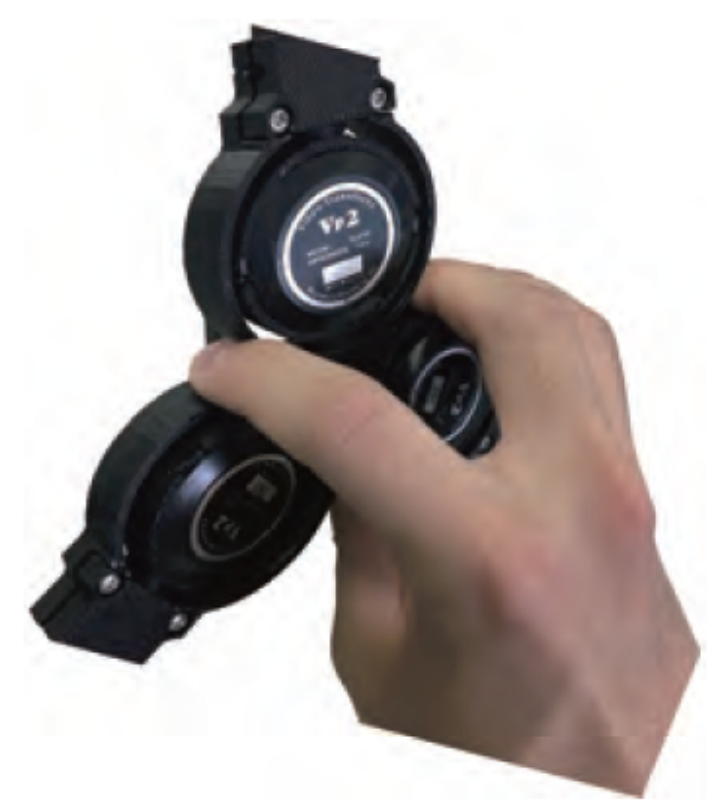

(b)

\section{Figure 9}

Two types of experimental devices and how to hold them. Type-1 as shown in (a) is designed so that it can be easily gripped with three fingers by providing a recess in the base of this device, and the modules are separated from each other. Type 2 as shown in (b) is arranged so that each module is closest to each other, and users can directly touch each module by grasping it with the recess of the outer frame 


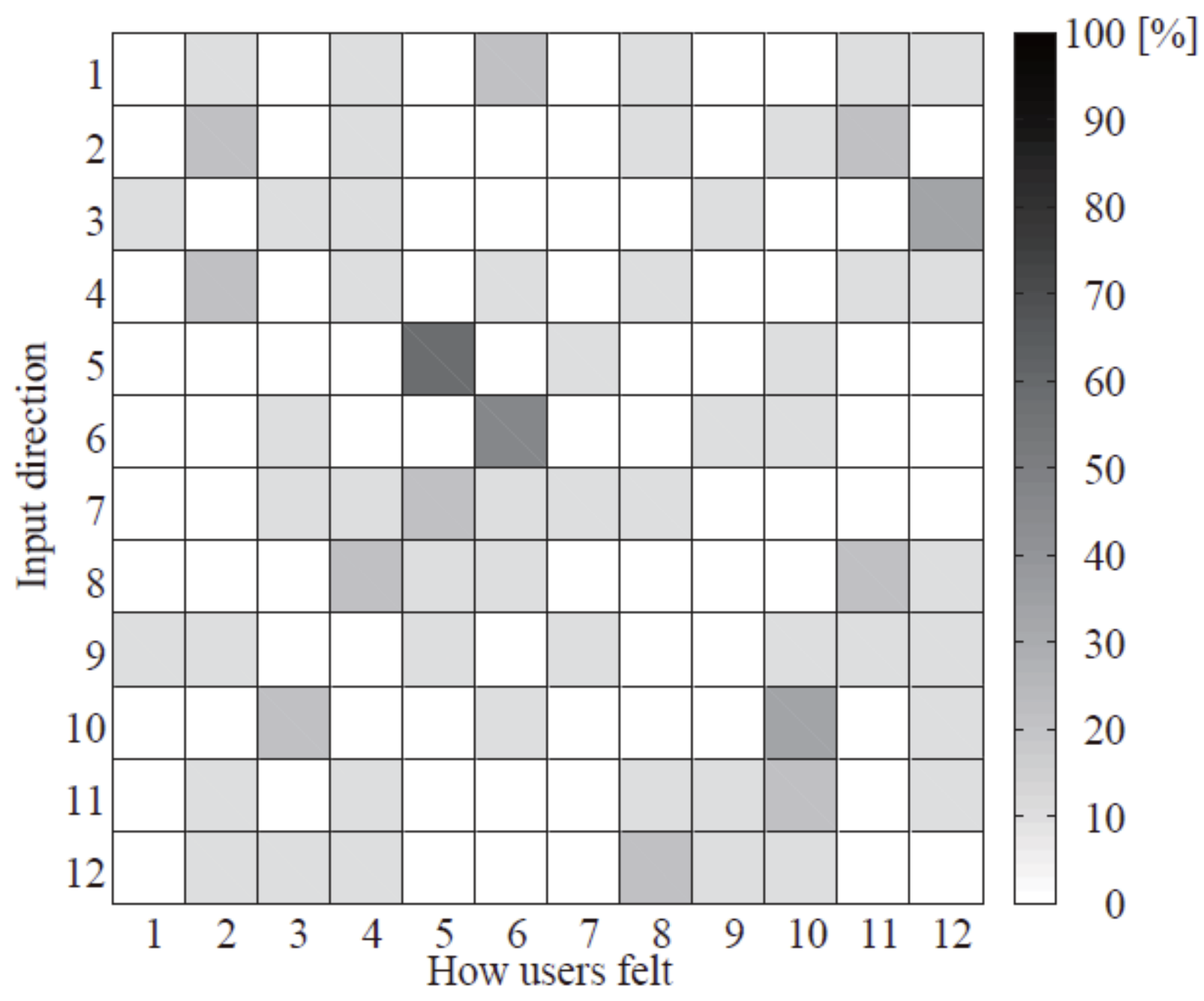

Figure 10

A heatmap representation of the user test result with the type-1 devices shown in Table 2 


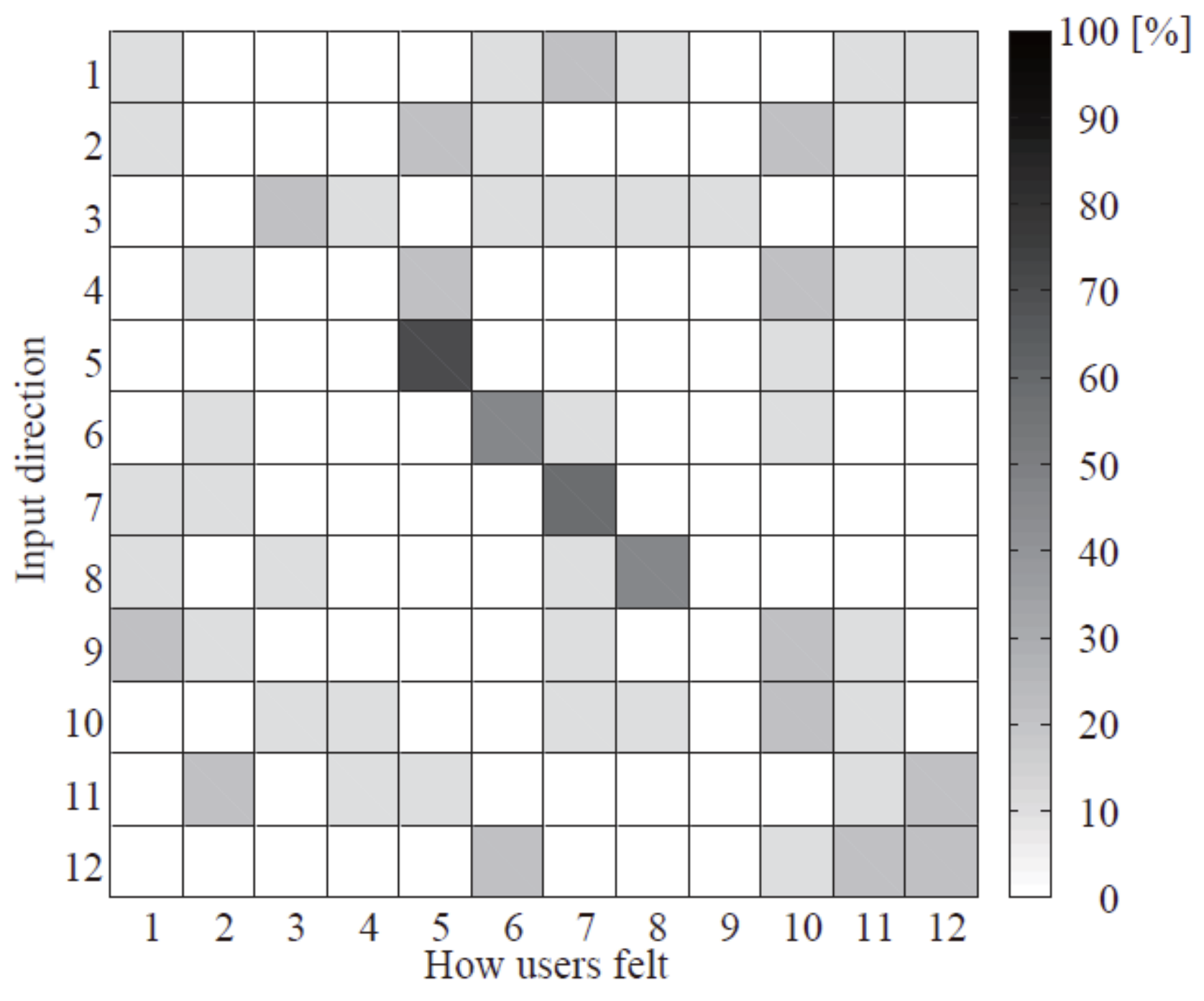

Figure 11

A heatmap representation of the user test result with the type-2 devices shown in Table 3

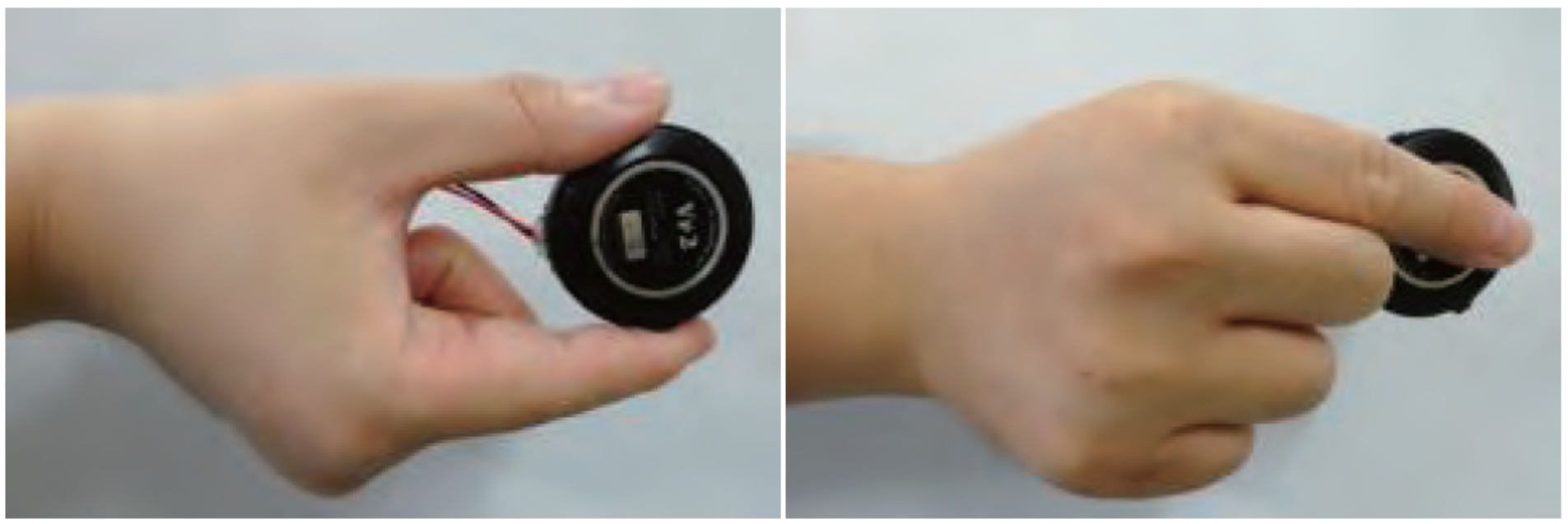

Figure 12 
How to hold the vibrator Vp2 [17], which is thought to contribute to the sensitivity of traction sensation perception 